\title{
PENGEMBANGAN MECHANIC CUTTING DENGAN TIGA DERAJAT KEBEBASAN BERBASIS BALLSCREW
}

\author{
Suroso, Aryanda Lukmana, Nugroho Tri Sanyoto \\ Sekolah Tinggi Teknologi Nuklir-BATAN \\ Email : surosohadi09@gmail.com
}

ABSTRAK

$\mathrm{T}$

lah dilakukan pengembangan mecahnic Cutting dengan tiga derajat kebebasan berbasis ballscrew yang bertujuan

dapat melakukan pemotongan material lembaran atau plat untuk skala laboratorium. Mechanic cutting ini dirancang menggunakan ballscrew dan linear guideway dan motor stepper, untuk melakukan gerak axis horisontal X dan Y serta gerak axis vertikal Z. Perhitungan dilakukan terhadap pemilihan komponen mechanic cutting agar mampu melakukan gerak untuk 3 derajat kebebasan. Hasil dari disain didapat diameter ballscrew $1 / 2$ inch, torsi sebesar $4,87 \mathrm{~mm}$, hasil pengujian mekanik untuk sumbu X sejauh $300 \mathrm{~mm}$ dengan kecepatan geser $5 \mathrm{~mm} / \mathrm{s}$, sumbuY sejauh $200 \mathrm{~mm}$ dengan kecepatan geser $5 \mathrm{~mm} / \mathrm{s}$, serta pada sumbu Z sejauh $75 \mathrm{~mm}$ dengan kecepatan geser 12,5 mm/s dan galat gerakan sebesar $0,14 \%$.

Kata Kunci: mechanic cutting, tiga derajat kebebasan ,ballscre.

\section{PENDAHULUAN}

Setiap mesin dirancang dan dibuat untuk memberikan fungsi yang dapat meringankan manusia, termasuk untuk pekerjaan yang rutin dan berulang. Untuk pekerjaan pengolahan dan pemotongan material lembaran atau plat yang berulang dan mengurangi kesalahan, dibutuhkan alat potong mekanis yang bersifat otomatis.

Saat ini di pasaran banyak tersedia bermacammacam alat potong mekanis yang sudah otomasi, termasuk diantaranya yang berbasis Computer Numerically Controlled (CNC) (Sudarno, 2016). Perangkat mesin CNC memerlukan biaya yang tinggi dan volume unit pengendali yang besar, sehingga masih sedikit perusahaan yang mempunyai keberanian dalam mempelopori investasi dalam teknologi ini. Beberapa mesin potong yang sudah ada, seperti laser cutting, juga belum bisa melakukan proses pemotongan untuk material tertentu karena cara pemotongan maupun sifat material yang akan dipotong tidak sesuai dengan sifat laser.

Demi mengatasi masalah ini, dilakukanlah penelitian mengenai rancang bangun mechanic cutting menggunakan ballscrew dengan tiga derajat kebebasan yang memanfaatkan prinsip kerja motor stepper dan sistem mekanik berupa ballscrew dan linear guideway. Para penggiat mesin dapat membuat sistem mekanik cutting sendiri menggunakan 
bahan-bahan yang mudah diperoleh di pasaran.

Pemilihan sistem gerak mekanik dengan menggunakan ballscrew bertujuan untuk mendapatkan konversi gerak rotasi dari motor penggerak menjadi gerakan linear dengan sedikit gesekan antara nuts atau bantalan bola. Dengan sistem gerak mekanik ballscrew akan kecil kemungkinan terjadi selip antara bantalan bola dengan ulir, sehingga mampu menahan kapasitas beban yang berat dengan umur yang panjang, mempermudah perawatan, keawetan sparepart, serta kebutuhan oli pelumas yang sedikit (Hiwin, 2014).

Rancang bangun sistem mekanik cutting berbasis ballscrew ini bertujuan untuk percobaan khususnya untuk pemotongan material lembaran/plat di laboratorium.

\section{TEORI}

\section{Ballscrew}

Ballscrew disebut juga dengan ball bearing screw (Gambar 1), yang terdiri atas spindle screw dan nut. Ballscrew adalah sistem gerak mekanik yang mengubah gerak rotasi menjadi gerak linear dengan sedikit gesekan. Terdiri dari spindle screw dan mur yang terintegrasi dengan bola bantalan dan mekanisme pengembalian bola bantalan berupa return tubes atau return cap, ballscrew menjadi sistem penggerak yang paling umum digunakan dalam aktuator permesinan. Ketika mendapat be- ban transmisi, beban seperti diteruskan ke bantalan bola, beban dipindah dari sekrup ke bola, dari bola ke mur, dan dari mur ke perangkat didorong atau dipindah, sehingga bola bergulir antara poros sekrup dan mur untuk mencapai efisiensi yang tinggi. Hal ini hanya memerlukan sepertiga daya torsi dibanding sekrup biasa, dan menjadikan ballscrew tidak hanya mampu mengubah gerak rotasi ke gerak lurus, tetapi juga mengubah gerak lurus ke gerak rotasi., dengan kestabilan tinggi, reversibility dan efisiensi tinggi jika dibandingkan dengan sekerup biasa.(Hiwin,2014).

Perhitungan untuk mendapatkan ukuran diameter ulir pada ballscrew (L.Mott,2004) agar mampu mengangkat beban tabung sinar X maka perlu dilakukan perhitungan dengan menggunakan persamaan (1):

$$
\begin{gathered}
A_{t}=\frac{F}{\sigma_{d}} \text { dan } \\
A_{s}=\frac{F}{\sigma_{d}}
\end{gathered}
$$

dengan:

$$
\begin{aligned}
& \text { At : Luas bidang tegangan tarik poros } \\
& \text { ballscrew }\left(\mathrm{cm}^{2}\right) \\
& \text { At : Luas bidang tegangan geser poros } \\
& \text { ballscrew }\left(\mathrm{cm}^{2}\right) \\
& \mathrm{F}: \text { Beban }(\mathrm{kg}) \\
& \text { od : Tegangan Tarik }\left(\mathrm{kg} / \mathrm{cm}^{2}\right) \\
& \mathrm{Kt}: \text { Nilai disain awal }
\end{aligned}
$$

Nilai disain awal untuk dari diameter ball 
screw ditemukan dari luas bidang At dan As. Beban $\mathrm{F}$ maksimum yang disarankan dapat dihitung dari persamaan (3) (Sularso, 1997) :

$$
\mathrm{P} \leq \mathrm{F}_{1} \cdot \mathrm{N}_{\mathrm{t}}
$$

dengan F1 adalah bidang dukung ulir sekrup, sedangkan Nt adalah tekanan bidang yang diperbolehkan antara poros (diameter ballscrew) dan tabung ulir (nut).

Apabila tinggi nut diumpamakan dengan $\mathrm{H}$ dan $\mathrm{S}$ adalah jarak puncak ulir, maka tabung ulir/nut ballscrew mempunyai $\mathrm{H} / \mathrm{S}$ jalan sekrup. Luas bidang jadi kita dapat dengan persamaan (4)(Khurmi, 2005)]:

$$
F_{1}=\frac{H}{S} \cdot \frac{\pi}{4}\left(d^{2}-d k^{2}\right)
$$

Dengan:

$$
\text { P : Beban }(\mathrm{kg})
$$

$\mathrm{H} \quad$ : Tinggi tabung $(\mathrm{mm})$

d : Diameter luar ulir (mm)

S : Jarak puncak ulir (mm)

$\mathrm{dk} \quad$ : Diameter tengah teras poros ulir $(\mathrm{mm})$

Nt : Tekanan bidang yang diperbolehkan antara batang ulir dan tabung

\section{Linear Guideway}

Linear Guideway adalah salah satu mekanisme yang memudahkan untuk gerakan linear, ditunjukkan pada Gambar1. Linear guideway memanfaatkan rolling elements seperti bola-bola yang kecil agar koefisien gesek semakin kecil. Dengan me- manfaatkan sirkulasi ulang rolling element antara rail dan block, linear guideway dapat mencapai gerakan lurus yang presisi jika dibandingkan dengan slide yang tradisional (Hiwin, 2014). Linear guideway atau disebut juga motorized Linear Stage banyak dipergunakan pada rancang bangun untuk $\mathrm{CNC}$, penggerak untuk gerak-gerak presisi yaitu untuk gerakan spindle memotong bahan.

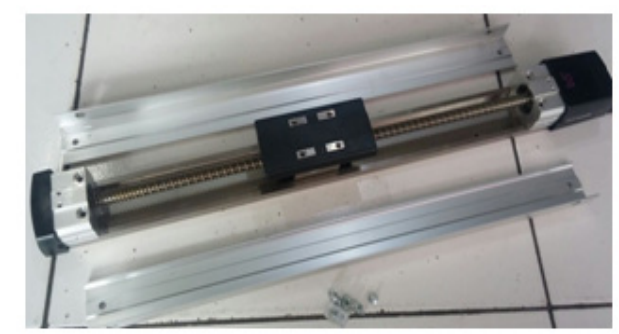

Gambar 1. Ballscrew dan Linear Guideway Pemilihan motor dan perhitungan torsi motor.

Untuk pemilihan motor yang berfungsi sebagai penggerak untuk menaikkan dan menurunkan gerak pemotongan dipilih motor stepper (Hartono, 2014). Torsi yang digunakan untuk menggerakkan beban memutar roda gigi dapat dihitung dengan persamaan 5. Apabila $\tan \lambda=\mathrm{p} / \pi \mathrm{Dp}$ dari lead angle $\mathrm{L}=1 / \mathrm{n}$ ( $\mathrm{n}=$ jumlah thread per inch) (L.Mott, 2004), maka Torsi:

$$
T_{u}=\frac{F \cdot D_{p}}{2}\left[\frac{\cos \phi \cdot \tan \lambda+f}{\cos \phi-f \cdot \tan \lambda}\right]
$$

dengan

$\mathrm{Tu} \quad$ : torsi untuk gerak naik (lb.in)

F : beban spindle (lb)

Dp : diameter jarak bagi minimum (inchi)

f : koefisiean gesekan 0,15 
Sedangkan Torsi untuk turun dapat dihitung dengan rumus persamaan (6) yaitu:

$$
T_{d}=\frac{F \cdot D_{p}}{2}\left[\frac{f-\cos \phi \tan \lambda}{\cos \phi+f \cdot \tan \lambda}\right]
$$

dengan :

Td : torsi untuk gerka turun (lb.in)

F : beban spindle (lb)

Dp: diameter jarak bagi minimum (inchi)

F : koefisiean gesekan 0,15

Perhitungan rangka mekanik cutting

Perhitungan pada rangka mekanik penumpu untuk spindle gerak naik-turun (axis Z) yaitu, tegangan yang bekerja pada body penumpu spindle dapat berupa kombinasi tegangan, bengkok dan geser juga tegangan yang lain.

Rangka mekanik dapat ditentukan dengan memperhitungkan beban dari spindle. Bahan menggunakan AISI 1040 Steel Bar. denganYield Strength Sy $=42000$ Psi (L. Mott, 2004):

Adapun untuk menghitung dimensi rangka:

$$
\begin{aligned}
& \sigma=\mathrm{M} / \mathrm{S} \\
& \sigma=\sigma \mathrm{d}=\mathrm{Sy} / \mathrm{N}
\end{aligned}
$$

dengan : $\mathrm{S}:$ Section modulus $=$ t.h2/6

$\mathrm{h}: 3 \mathrm{t}$

$\mathrm{N}$ : disain factor

\section{Arduino Uno}

Arduino Uno adalah board berbasis mikrokontroler pada ATmega328. Board ini memiliki 14 pin digital masukan / keluaran (dimana 6 pin dapat digunakan sebagai keluaran PWM), 6 masukan analog, 16 MHz osilator kristal, koneksi USB, dan tombol reset. Pin-pin ini berisi semua yang diperlukan untuk mendukung mikrokontroler, hanya terhubung ke komputer dengan kabel USB atau sumber tegangan bisa didapat dari adaptor AC-DC atau baterai untuk menggunakannya.

\section{Driver Motor Stepper TB6560}

Merupakan driver motor stepper sebagai penerjemah untuk pengoperasian motor stepper dengan mudah . Perangkat dirancang untuk mengoperasikan motor stepper bipolar dengan langkah full , half , eight (1/8) dan sixteenth (1/16) depending mode.

Modul ini sangat mudah digunakan, tidak memerlukan instruksi karena semua pengaturan telah tercetak di papan modul dan dirancang agar mudah melepas panas. Tegangan masukan sebesar 10-35 Volt DC dan dapat menggerakkan motor stepper sampai dengan 3 Amper.

\section{METODE PENELITIAN}

Metode Diagram alir mencerminkan langkah-langkah yang dilakukan dalam pengembangan pengembangan sistem mekanik cutting dari disain awal, penentuan komponen komponen yang harus 
ada, material dari masing-masing komponen, dan ketersediaan.

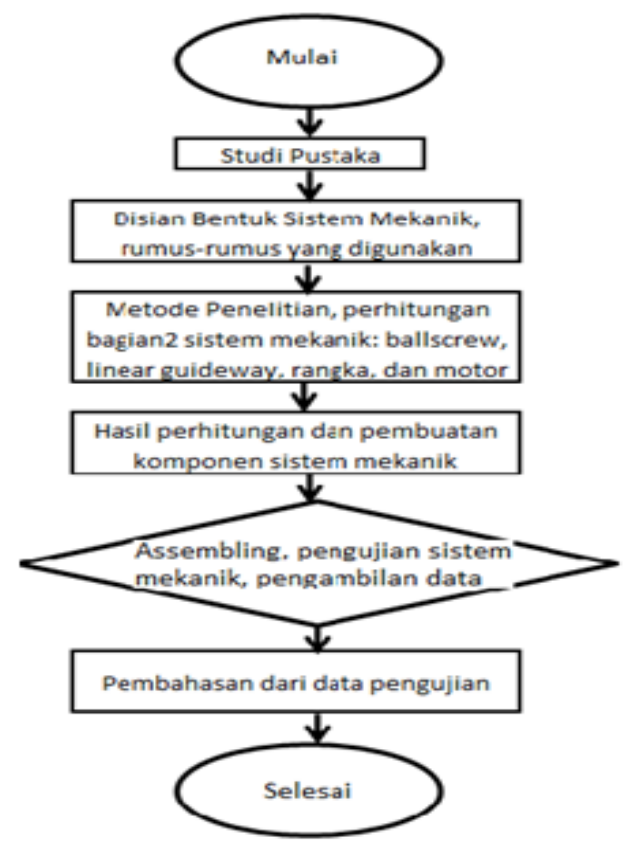

Gambar 2. Diagram alir pengembangan sistem mekanik cutting

Dalam disain juga diperhitungkan atau disesuaikan dengan aspek kemudahan pembuatan. Berdasarkan perhitungan dan rumus-rumus diatas dengan metode seperti ditunjukkan pada diagram Gambar.2, maka didapatkan hasil perhitungan berupa dimensi dari ballscrew, linear guideway, motor, dan rangka dari sistem pengembangan mechanical cutting yang kemudian dilanjutkan dengan pembuatan /machining.

\section{HASIL DAN PEMBAHASAN}

Perhitungan motor penggerak

Kecepatan gerak linear naik dan turun yang dibutuhkan direncanakan $5 \mathrm{~cm} /$ detik. Untuk men- gangkat gerak naik dan turun(spindle Z), motor penggerak sekurang-kurangnya harus memenuhi besaran torsi sesuai dengan perhitungan. Apabila diketahui beban spindle ditentukan $80 \mathrm{~kg}$ At dan As dari tabel diameter ballscrew 1/4 inch dibulatkan $1 / 2$ inch bahwa $\mathrm{p}=0,125$ maka sudut kisarnya yaitu $\lambda$ $=\tan -1 \mathrm{p} / \pi \mathrm{Dp}=\tan -10,125 /(3.14 \times 0,5)=11,983^{\circ}$. Dengan menggunakan persamaan (6) maka torsi yang dibutuhkan untuk mengangkat beban dihitung sebagai berikut:

Dengan $\cos \varnothing=\cos 14,5^{\circ}=0,986, \tan \lambda=\tan 11,98^{\circ}$ $=0,212^{\circ}$, berat $80 \mathrm{~kg}=176 \mathrm{lb}$, maka:

$$
\mathrm{Tu}=\frac{220.0 ; 5408}{2}\left[\frac{(0 ; 968)(0 ; 212)+0 ; 15}{0 ; 968-(0 ; 15)(0 ; 212)}\right]=22,51 \text { lb.in }
$$

Dengan cara yang sama, menggunakan persamaan (5) dan (6) dapat dihitung kebutuhan torsi untuk menurunkan beban, didapat $\mathrm{Td}=12,20 \mathrm{lb}$.in . Dengan torsi untuk menaikan beban yang dibutuhkan sebesar 22,551 lb.in dan torsi untuk menurunkan beban sebesar 12,20 lb.in maka perlu dipilih motor steper dengan torsi yang mampu mengangkat 25 lb.in (dibulatkan), yaitu digunakan untuk menaikan atau menurunkan beban. Dapat juga dihitung dengan perhitungan $\mathrm{Fa}=$ frictional resistance $=\mu \mathrm{x}$ beban $\mathrm{x}$ grafitasi, dengan $\mu$ adalah rolling frictional coefficient $=0,003$ ), beban $40 \mathrm{~kg}$ dengan angka keamanan $=2$ sehingga beban dianggap $80 \mathrm{~kg}$, akhirnya $\mathrm{Fa}=0,003 \times 80 \mathrm{~kg} \times 9,8=2,94$ Newton. 


$$
T=\frac{F a \cdot 10}{2 \pi \cdot 0.96}=\frac{2,94 \cdot 10}{2 \pi \cdot 0.96}=4,87 \mathrm{~N} \cdot \mathrm{mm}
$$

\section{Perhitungan rangka tabung sinar $\mathrm{X}$}

Ukuran tinggi penumpu atau rangka untuk gerak naik-turun ditentukan secara umum spindle bergerak mempunyai tinggi $30 \mathrm{~cm}$ sehingga tinggi frame body untuk menggerakkan beban tabung dipilih dari besi / steel bar memiliki panjang mnimal $40 \mathrm{~cm}$ dan ukuran luas penampang $\mathrm{h}$ dan $\mathrm{t}$.

Jika bahan dipilih AISI 1040 Steel Bar, maka Yield Strenght Sy $=42000$ psi, design factor $(\mathrm{N})=$ 2, design stress $\sigma d=42000 / 2=21000$ psi. akhirnya didapat ukuran material rectangular bar $6 \times 4 \times 1 / 4$.

\section{Desain Sistem Mekanik}

Desain awal sistem mekanik terdapat pada Gambar 1. Dalam perancangan terdapat komponenkomponen penyusun alat berupa kerangka utama, 3 set ballscrew dan linear guideway masing-masing pada sumbu x, y, dan z, motor stepper 3 buah, bor DC dan meja kerja.

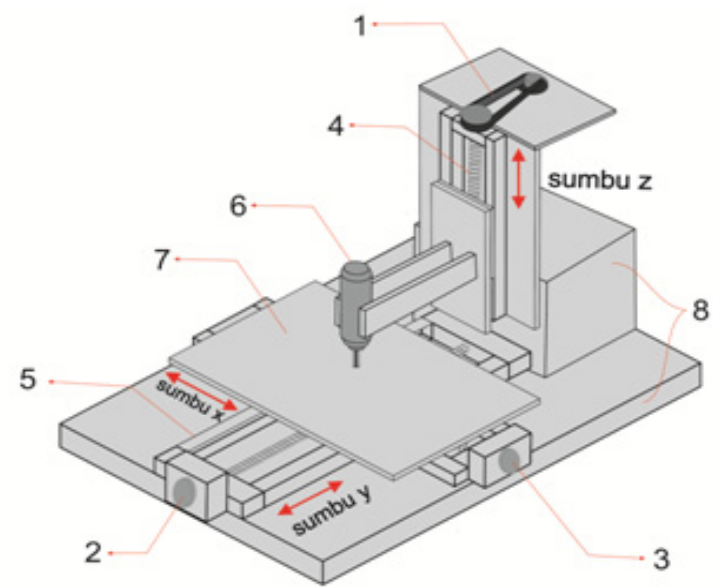

Gambar 3. Disain awal sistem mekanik cutting
Keterangan:

1. Motor Stepper Z 5. Linear Guideway

2. Motor Stepper Y 6. Bor DC

3. Motor stepper X 7. Meja kerja
4. Ballscrew
8. Kerangka

Parameter Beban dan Daya antara yang Dibutuhkan dan yang Digunakan

Dari hasil perhitung diketahui bahwa semua parameter yang hendak digunakan harus memenuhi syarat maksimum beban yang diijinkan dan minimum daya yang dibutuhkan.

\section{Desain Dudukan Sumbu Z}

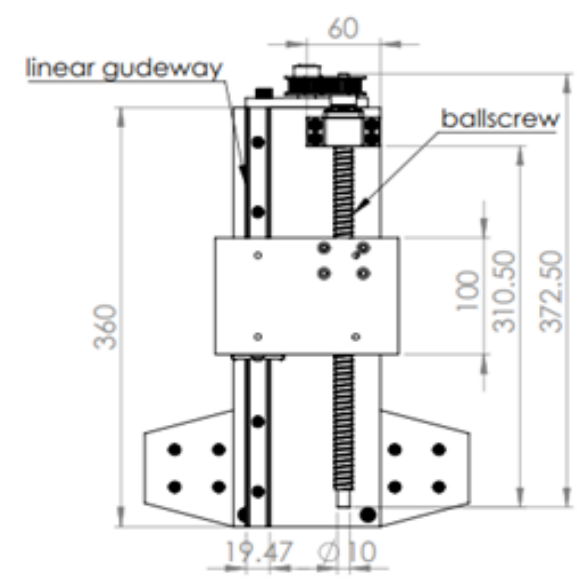

Gambar 4. Desain dudukan sumbu z.

\section{Desain Kerangka Utama}

Desain kerangka utama berfungsi sebagai dudukan ballscrew dan tempat rangkaian elektronika.

Bahan yang digunakan untuk membuat kerangka utama adalah besi tuang dengan ketebalan $8 \mathrm{~mm}$. 


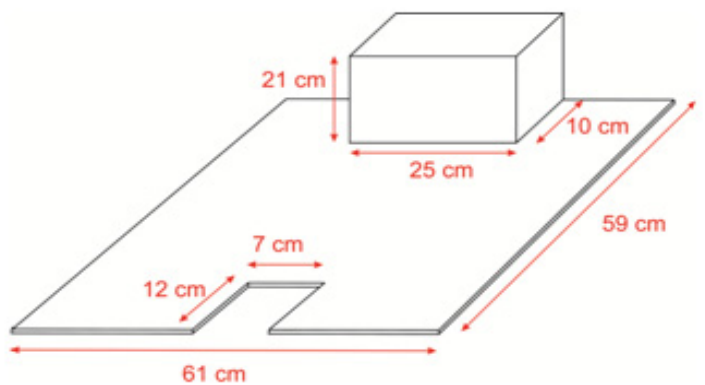

Gambar 4 Disain kerangka utama

\section{Desain Dudukan Sumbu X}

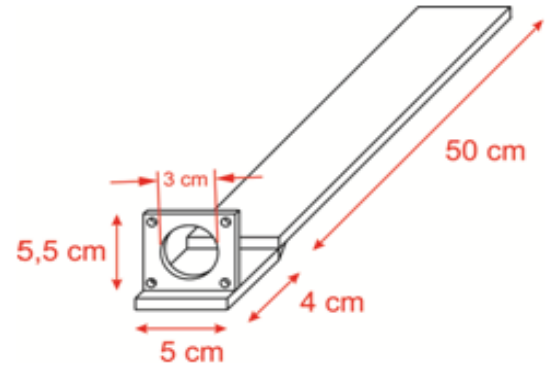

Bagan 5 Disain dudukan sumbu X

\section{HASIL PENELITIAN}

Hasil rancang bangun pada penelitian ini terdapat pada Gambar 6.

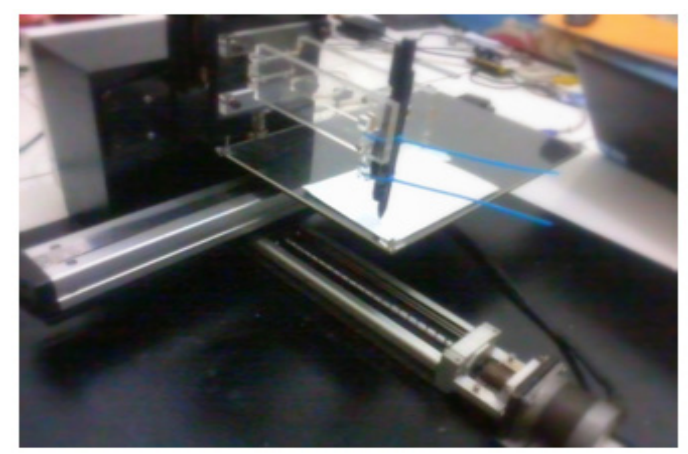

Gambar 6. Hasil rancang bangun mechanic cutting

\section{Uji Kestabilan dan Keakurasian}

Pengujian kestabilan dilakukan dengan mengukur waktu tempuh alat untuk bergerak pada jarak tertentu. Pengujian keakurasian yaitu dengan memberikan input nilai pada alat lalu mengukur jarak nyata yang ditempuh benda. Pengujian dilakukan dengan menggunkan fitur machine control pada universal g-code sender.

Tabel 1 Pengujian Kestabilan sumbu X

\begin{tabular}{|r|c|c|c|c|}
\hline No & $\begin{array}{c}\text { Jarak } \\
(\mathrm{mm})\end{array}$ & $\begin{array}{c}\text { Waktu } \\
(\text { detik })\end{array}$ & $\begin{array}{c}\text { Kecepatan } \\
\text { geser } \\
\text { (mm/detik) }\end{array}$ & $\begin{array}{c}\text { Putaran } \\
(\mathrm{rpm})\end{array}$ \\
\hline 1. & 100 & 20 & 5 & 50,7 \\
\hline 2. & 150 & 30 & 5 & 50,7 \\
\hline 3. & 200 & 40,5 & 4,9 & 50,7 \\
\hline 4. & 250 & 49,5 & 5,05 & 50,7 \\
\hline 5. & 300 & 60 & 5 & 50,7 \\
\hline
\end{tabular}

Tabel 2. Hasil Uji Galat Gerakan Sumbu X

\begin{tabular}{|c|c|c|}
\hline $\begin{array}{c}\text { jarak yang } \\
\text { diberikan } \\
(\mathrm{mm})\end{array}$ & $\begin{array}{c}\text { jarak } \\
\text { terukur } \\
(\mathrm{mm})\end{array}$ & Galat (\%) \\
\hline 60 & 60 & 0 \\
\hline 120 & 120 & 0 \\
\hline 180 & 180 & 0 \\
\hline 240 & 240 & 0 \\
\hline 300 & 300 & 0 \\
\hline
\end{tabular}

Tabel 3 Penguiian Kestabilan Sumbu Y

\begin{tabular}{|c|c|c|c|c|}
\hline No & $\begin{array}{c}\text { Jarak } \\
(\mathrm{mm})\end{array}$ & $\begin{array}{c}\text { Waktu } \\
\text { (detik) }\end{array}$ & $\begin{array}{c}\text { Kecepatan } \\
\text { geser } \\
(\mathrm{mm} / \text { detik) }\end{array}$ & $\begin{array}{c}\text { Putaran } \\
\text { (rpm) }\end{array}$ \\
\hline 1. & 40 & 7,95 & 5,03 & 30 \\
\hline 2. & 80 & 16 & 5 & 30 \\
\hline 3. & 120 & 24 & 5 & 30 \\
\hline 4. & 160 & 32 & 5 & 30 \\
\hline 5. & 200 & 40,2 & 4,98 & 30 \\
\hline
\end{tabular}

Tabel 4 Hasil Uji Galat Gerak Sumbu Y

\begin{tabular}{|c|c|c|}
\hline $\begin{array}{c}\text { jarak yang } \\
\text { diberikan } \\
(\mathrm{mm})\end{array}$ & $\begin{array}{c}\text { jarak } \\
\text { terukur } \\
(\mathrm{mm})\end{array}$ & Galat (\%) \\
\hline 40 & 40 & 0 \\
\hline 80 & 80 & 0 \\
\hline 120 & 120 & 0 \\
\hline 160 & 160 & 0 \\
\hline 200 & 200 & 0 \\
\hline
\end{tabular}


Tabel 5 Pengujian Kestabilan Sumbu Z

\begin{tabular}{|c|c|c|c|c|}
\hline No & $\begin{array}{c}\text { Jarak } \\
(\mathrm{mm})\end{array}$ & $\begin{array}{c}\text { Waktu } \\
(\text { detik })\end{array}$ & $\begin{array}{c}\text { Kecepatan } \\
\text { geser } \\
(\mathrm{mm} / \text { detik) }\end{array}$ & $\begin{array}{c}\text { Putaran } \\
(\mathrm{rpm})\end{array}$ \\
\hline 1. & 15 & 1,19 & 12,6 & 83,3 \\
\hline 2. & 30 & 2,4 & 12,5 & 83,3 \\
\hline 3. & 45 & 3,6 & 12,5 & 83,3 \\
\hline 4. & 60 & 4,8 & 12,5 & 83,3 \\
\hline 5. & 75 & 6 & 12,5 & 83,3 \\
\hline
\end{tabular}

Tabel 6 Hasil Uji Galat Gerak Sumbu Y

\begin{tabular}{|c|c|c|}
\hline $\begin{array}{c}\text { jarak yang } \\
\text { diberikan } \\
(\mathrm{mm})\end{array}$ & $\begin{array}{c}\text { jarak } \\
\text { terukur } \\
(\mathrm{mm})\end{array}$ & Galat (\%) \\
\hline 15 & 14,95 & 0,33 \\
\hline 30 & 29,95 & 0,17 \\
\hline 45 & 44,95 & 0,11 \\
\hline 60 & 60 & 0 \\
\hline 75 & 74,95 & 0,07 \\
\hline
\end{tabular}

Uji Menggambar

Pengujian dengan tes menggambar dilakukan sebagai simulasi alat ketika akan digunakan untuk memotong material. Caranya dengan memasang sebuah pena pada dudukan aktuator dengan media gambar berupa kertas. Gambar yang akan dieksekusi berupa garis vertikal, horizontal dan diagonal yang berpotongan pada titik tengah serta 4 lingkaran masing-masing dengan diameter $2 \mathrm{~cm}$, $4 \mathrm{~cm}, 6 \mathrm{~cm}$ dan $8 \mathrm{~cm}$.

\section{Uji Memotong Material}

Pengujian pemotongan material dilakukan dengan menggunakan bor de dengan diameter mata potong sebesar $2,2 \mathrm{~mm}$ sebagai pemotong dan bahan yang akan dipotong berupa sterofoam den- gan ketebalan $10 \mathrm{~mm}$. Bentuk yang akan dibuat berupa lingkaran dengan diameter $40 \mathrm{~mm}$. Kecepatan makan diatur sebesar $50 \mathrm{~mm} /$ menit. Gambar 7 adalah pola yang akan dibuat dan Gambar 8 adalah hasilnya.

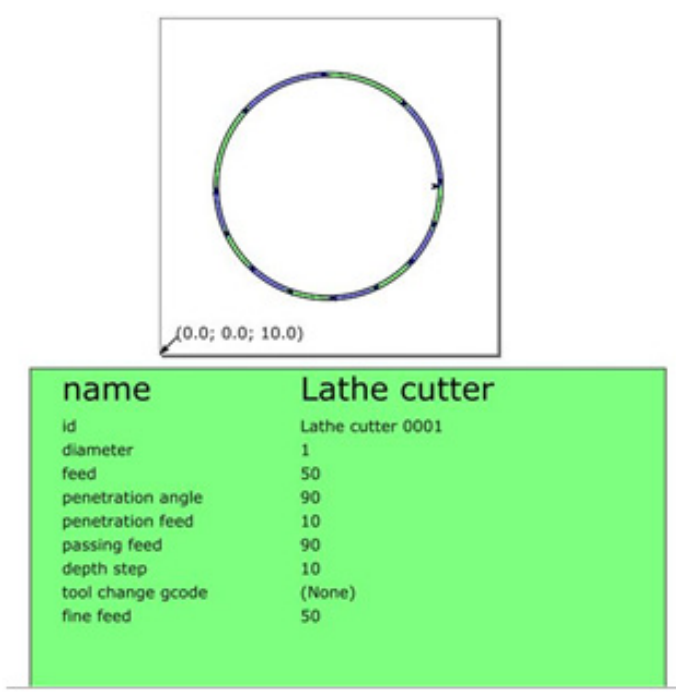

Gambar 7. Pola yang akan dibuat

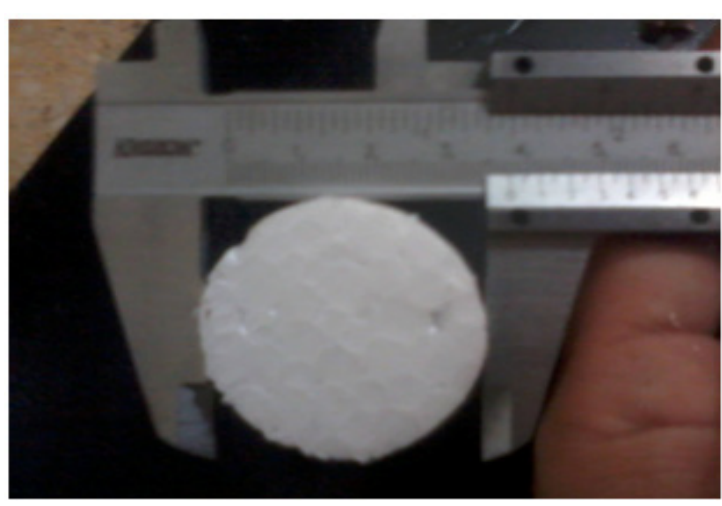

Gambar 8. Hasil pemotongan sterofoam

\section{KESIMPULAN}

Berdasarkan pengembangan yang telah dilakukan dapat diambil beberapa kesimpulan sebagai berikut:

1. Alat yang dibuat sesuai perencanaan berupa alat mechanic cutting dengan ukuran diameter mekanik ballscrew $1 / 2$ inch dan torsi motor sebesar 
4,87 Nmm mampu digunakan untuk melakukan gerak axis horisontal $\mathrm{X}$ dan $\mathrm{Y}$ serta gerak axis vertikal $\mathrm{Z}$ untuk 3 derajat kebebasan.

2. Hasil pengujian mekanik untuk sumbu $X$ sejauh $300 \mathrm{~mm}$ dengan kecepatan geser $5 \mathrm{~mm} / \mathrm{s}$, sumbuY sejauh $200 \mathrm{~mm}$ dengan kecepatan geser 5 $\mathrm{mm} / \mathrm{s}$, serta pada sumbu $\mathrm{Z}$ sejauh $75 \mathrm{~mm}$ dengan kecepatan geser $12,5 \mathrm{~mm} / \mathrm{s}$

3. Galat gerakan sebesar $0,14 \%$

\section{DAFTAR PUSTAKA}

HIWIN, HIWIN Ballscrew Technical Information. Minsk : Belarussia,2014.

Khurmi RS, Gupta JK, A Text Book Of Machine Design, Eurasia Publishing House LTD, New Delhi, 2005

Puji Hartono, Muhammad Naufal Fauzi, “ Pengendalian Otomasi 3 Axis Berbasis PLC Pada Simulasi Proses Las”, Metal Indonesia Vol. 36 No.1, 2014

Robert L. Mott, Machine Elements in Mechincal Design, Prentice Hall, 2004.

Sudarno, Martono, Sholeh Mauludin, "Rancang Bangun Mesin CNC Router Berbasis Arduino", Politeknosains Vol XV No.2, 2016

Sularso, Dasar Perencanaan dan Pemilihan Elemen Mesin, Pradnya paramita, Jakarta,1997 